University of Wollongong

Research Online

Faculty of Business - Papers (Archive)

Faculty of Business and Law

$1-1-2017$

How do materialists choose prominent brands in emerging markets?

Vida Siahtiri

Macquarie University

Wai Jin J. Lee

University of Wollongong, thlee@uow.edu.au

Follow this and additional works at: https://ro.uow.edu.au/buspapers

Part of the Business Commons

Research Online is the open access institutional repository for the University of Wollongong. For further information contact the UOW Library: research-pubs@uow.edu.au 


\title{
How do materialists choose prominent brands in emerging markets?
}

\author{
Abstract \\ Materialism is a worldwide phenomenon. However, our knowledge about the effect of materialism on \\ consumer brand choice is limited. This study unlocks the path from materialism to brand prominence \\ focusing on fashion, quality, and price consciousness. Our findings within the Chinese context show that \\ the paths from materialism to fashion, quality, and price consciousness are positive. Further, we found \\ that the paths from fashion and quality conscious to brand prominence are positive, while the path from \\ price conscious to brand prominence is negative but not significant. These findings have significant \\ implications for brand managers in emerging markets.

\section{Disciplines} \\ Business

\section{Publication Details} \\ Siahtiri, V. \& Lee, W. (2019). How do materialists choose prominent brands in emerging markets?. Journal \\ of Retailing and Consumer Services, 46 133-138.
}




\title{
How do materialists choose prominent brands in emerging markets?
}

\begin{abstract}
:
Materialism is a worldwide phenomenon. However, our knowledge about the effect of materialism on consumer brand choice is limited. This study unlocks the path from materialism to brand prominence focusing on fashion, quality, and price consciousness. Our findings within the Chinese context show that the paths from materialism to fashion, quality, and price consciousness are positive. Further, we found that the paths from fashion and quality conscious to brand prominence are positive, while the path from price conscious to brand prominence is negative but not significant. These findings have significant implications for brand managers in emerging markets.
\end{abstract}

Key words: Materialism, brand prominence, emerging market.

\section{Introduction}

Owing to the incessant exposure to messages encouraging consumerism and promulgating materialism, consumers in emerging markets are constantly revamping their lifestyles. People in the emerging world such as China are increasingly emulating the Western-style material culture and indulging in luxury and prominent brands (O'Cass and Siahtiri, 2013). Indeed, being one of the biggest consumer markets in the world (Zhou et al., 2010), China is the focus of many multinational and Western firms due to its relatively strong economic growth and government policies developed to boost consumption (Zhang and Kim, 2013). China has experienced massive socio-political-economic changes, which have revolutionized consumption principles (Kaigler-Walker and Gilbert, 2009). As China continues communication with the rest of the world, the nation becomes more modernized and oriented 
towards branded products (Zhang and Kim, 2013). The modern Chinese consumers are now hungry for internationally famous lifestyle and fashion brands (Park et al., 2007). The younger Chinese generation in particular are inheriting materialism from their parents, believing that acquiring luxury items is the only path to demonstrate success and wealth, and gain satisfaction and happiness in their life (Zhang and Kim, 2013).

Considering the prevalence of materialism, the extant literature is replete with studies shedding light on the consumption patterns of materialistic individuals with the focus on brand engagement and brand attitude (Park et al., 2010; Park et al., 2007). An emerging stream of research even considers brand status as the missing link between materialism and brand engagement (Flynn et al., 2016). However, we still lack an understanding of the prominent attributes that consumers consider when purchasing a brand and the underlying mechanism through which their materialistic tendencies influence brand choice. This lack of understanding is especially evident for brands that are symbolic and address consumers' concern for prestige and status. In particular, little clarity has been offered from the perspective of an emerging market such as China, where consumers use brand with prominent attribute (e.g., imported brands) to demonstrate and express their social self and wealth (Zhang and Kim, 2013). To address these shortages in the literature we raise the research question: How do Chinese materialists choose prominent brands?

Using self-expansion theory (Aron et al., 2005), we extend the work by Flynn et al. (2016), Zhang and Kim (2013), Han et al. (2010), and Park et al. (2010), and unlock the underlying mechanism that connects materialism to brand prominence in an emerging market, China. We argue that consumers' materialistic values and beliefs influence the manner in which they evaluate and perceive brands, as captured by quality consciousness, fashion consciousness and price consciousness, which in turn affects the way they evaluate prominent attributes within brands (e.g., brand name and origin). We focus on the critical 
roles of consumers' quality, fashion and price consciousness because they reflect Chinese consumers' evaluation and perception of brands that help them establish a favorable social image (O'Cass and Siahtiri, 2013). Accordingly, they may help to explain how and why consumers pursuing the material lifestyle deploy them as extensions of their selves. We contribute to the literature on emerging market and self-expansion theory (Aron et al., 2005) by unpacking the link between materialism and brand prominence. Further, we contribute to practice by showing how marketing managers of branded goods can sharpen their marketing strategies targeted at materialistic consumers in emerging markets. Our conceptual framework is illustrated in Figure 1.

\section{--- Figure 1 Here---}

Figure 1: Conceptual Model

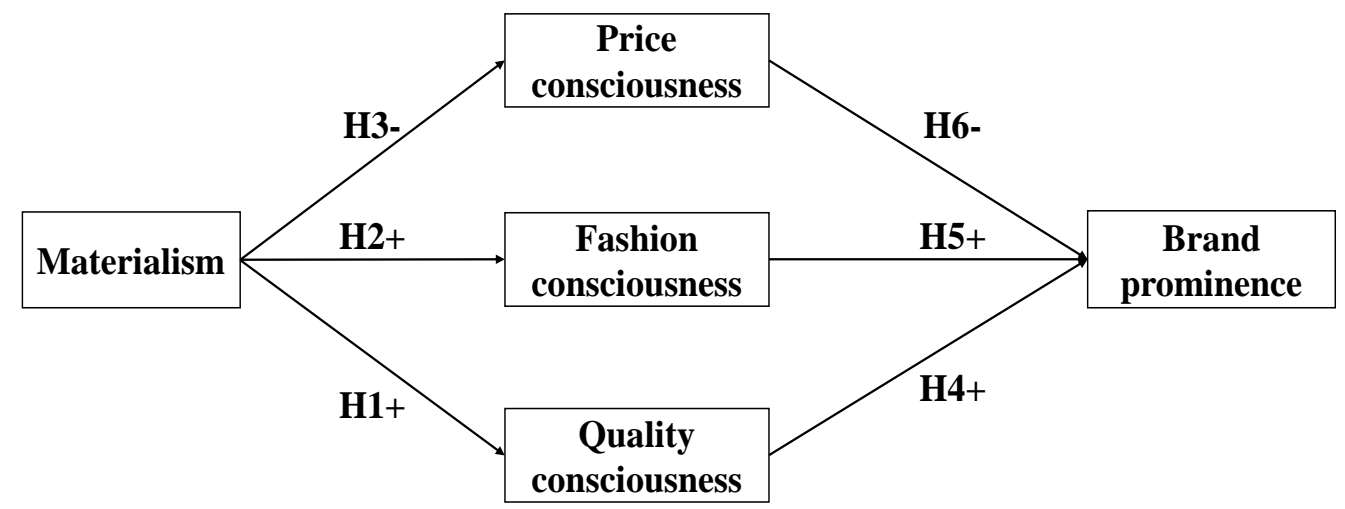

\section{Literature review}

\subsection{Materialism}

Materialism is seen as the importance of possessing worldly materials to demonstrate desired self-status (Belk, 1985; Richins and Dawson, 1992). Belk (1985) conceptualizes materialism as a set of negative personality traits including non-generosity, possessiveness, 
and envy. However, Richins and Dawson (1992, p. 308) believe materialism is "a set of centrally held beliefs about the importance of possessions in one's life'. In the view of Richins and Dawson (1992), materialism is a set of values that affect the way people perceive their surroundings and structure their lifestyles. Richins and Dawson (1992) believe materialists center their belief on three domains. First is acquisition centrality, which refers to placing possession and their acquisition to the center of life. Second is acquisition to pursuit happiness, which explains how materialists view possession to enhance their well-being and life satisfaction. Third is success, which is about judging self and others' success by the number and quality of possessions accumulated.

The literature on materialism presents two streams of research. The first stream supports the view of Richins and Dawson (1992), and shows that materialists display their success and social standing by possessing material objects (Heaney et al., 2005; Richins and Dawson, 1990 \& 1992). Researchers in this stream with a focus on China discuss how materialists select products that provoke reactions from others with the belief that acquiring material possessions conveys life happiness, satisfaction, and enjoyment (Chan et al., 2015). The second stream of research focuses on why materialists choose their preferred products. Research in this domain shows intrinsic reasons such as self-esteem, status and sense of achievement are some of the reasons for selection of specific products (Gil et al., 2012; Park et al., 2007; Heaney et al., 2005; Zhang and Kim, 2013). These behaviors are explained by self-expansion theory (Aron et al. 2005). According to this theory, people possess an inherent desire to integrate others or objects (e.g., brands) into their life to enhance their selfrealization. In this sense, materialists use branded products and services to project themselves as important and demonstrate a more favorable image to others because they tend to view the brand's resources as their own personal resources (cf, Park et al., 2010). 


\subsection{Brand prominence}

Consumers are said to favor products that are superior and possess prominent attributes (Evangelidis and Levav, 2013). Prominence describes situations in which some attributes are important than the other with respect to a choice criterion (Fischer et al., 1999). Identifying differences in attribute prominence is a basic component of most decision strategies (Evangelidis and Levav, 2013), where individuals give more weight to prominent attributes in their choices (Fischer et al., 1999). Previous studies have shown that brand prominence has a stronger effect on cognitive responses because it captures audience attention, provides an information processing advantage, and makes the brand more likely to be seen, saved, and retrieved from memory (van Reijmersdal et al., 2012; Han et al., 2010).

Review of research on brand prominence shows two streams of research. The first stream emphasizes self-brand connection, where the focus is on the extent consumers develop an emotional attachment to a brand that keeps the brand on the top of their mind (e.g., Park et al., 2010). The second stream of research focuses on visibility of brand attributes and how they appeal to consumers (e.g., Han et al., 2010). Given our study focuses on how materialists evaluate and choose brands, we adopt the second stream of research and examine the role of brand prominence in consumer decision-making. Extant literature suggests that brand name and its origin are among the most prominent attributes influencing consumer purchase decision because they reflect consumers' perception of quality and value in products (Park et al., 2007; Lim and O'Cass, 2001). For example, Zhang and Kim (2013) find that Chinese consumers are more likely to purchase name-brand products as a means to boost their own status. Similarly, O'Cass and Siahtiri (2014) find that Chinese consumers have higher evaluations of Western and imported brands than domestic brands. Therefore, building on prior research (e.g., Han et al., 2010; Park et al., 2007), we view brand prominence as the salience of brand name and origin within an individual's search and purchase process. 


\section{Hypothesis development}

\subsection{Materialism and quality consciousness}

Quality consciousness refers to a customer's tendency to seek for the brand's overall quality and excellence (cf. Zeithaml, 1988). Materialism is believed to influence the type, quality and quantity of goods purchased by individuals because these indicators are demonstration of success (Richins and Dawson, 1992) and who they are (Aron et al., 2005). Materialists are oriented towards buying higher quality products and services to intrinsically satisfy themselves (Eastman and Eastman, 2011) and explicitly communicate their wealth and success in life as quality products are associated with higher price. Within the context of China, materialists are said to gain face, self-esteem and recognition from significant others when they purchase branded products (Bao et al., 2003; Liao and Wang, 2009). For Chinese, branded products that are considered high in quality communicate prestige and who they are (Chan et al., 2015; O'Cass and Siahtiri, 2014). Thus, consumers in China pursuing the material lifestyle are more likely to be quality conscious because they satisfy their intrinsic happiness and it allow them to boost their status through achieving esteem and appreciation from others. Therefore,

H1: Materialism is positively associated with quality consciousness.

\subsection{Materialism and fashion consciousness}

Fashion consciousness refers to individuals' tendency to seek new and fashionable products (Gentina, et al.,, 2014). The literature suggests that consumers prefer to purchase brands that best match their personality (Mulyanegara, et al., 2009) and reflect who they are (Aron et al., 2005). It is also said that materialists select the type of products that are socially visible and can fulfill their desire to signal their social status (Gil et al., 2012; Richins and Dawson, 1992; Chan et al., 2015). Within the Chinese context, consumers maintain their 
social status by being more fashionable and buying new designs to communicate their status or individual achievements. Previous research suggests that Chinese consumers are highly involved with all fashion-related products as it allows them to gain social approval and recognition (O'Cass, et al., 2013). Chinese consumers are inspired to stand out from the crowd by showing their success and material achievement (Zhang and Kim, 2013; Chan, 2008) to maximize their intrinsic happiness and satisfaction with life. Therefore, Chinese consumers pursuing the material lifestyle are more likely to be fashion conscious because adopting latest fashion product allows them to signal their wealth, prestige, success, and to prove they are different (Chan et al., 2015). Therefore,

H2: Materialism is positively associated with fashion consciousness.

\subsection{Materialism and price consciousness}

Price consciousness is defined as "the degree to which the consumer focuses exclusively on paying a low price', (Lichtenstein et al., 1993, p. 235). Chinese consumers rely on highpriced products when they seek to display their wealth, achievement and status because it allows them to differentiate themselves from others who cannot afford these types of products (Kim and Jang, 2014). In this sense, Chinese consumers willingly pay a high price for products and brands with symbolic value so as to maintain their status, display wealth and maximize happiness (Zhang and Kim, 2013). Chinese consumers not only buy quality and functionality of products with the higher prices (O'Cass and Siahtiri, 2014), but purchase visibility, status, and demonstration of their success in personal life (Lichtenstein et al., 1993). Based on the above discussion, we expect that Chinese consumers are less concerned about price when purchasing products that help them acquire and reflect wealth, success, status, and intrinsic happiness. Therefore,

H3: Materialism is negatively associated with price consciousness. 


\subsection{Quality consciousness and brand prominence}

Brand prominence refers to the salience of a brand and its origin elements within an individual's search and purchase process (cf, Han et al., 2010). Quality conscious consumers are supposed to be perfectionists often emphasize searching for the highest or very best quality products. They have very high personal standards, and tend to shop more carefully and search for the best quality products (Wesley et al., 2006). Specifically, to reduce ambiguity and risks associated with purchases (e.g., financial loss), consumers often rely on product quality information. Accordingly, they tend to select established or well-known brands instead of trying new or unknown brands whose performance is less clear (Bao et al., 2003). Similarly, Chinese consumers are said to be more Western brand-oriented because they believe brands with stronger origins are of better quality (O'Cass and Siahtiri, 2013). Given the prominence of brand name and origin as critical indicators of product quality (Bao et al., 2003; Rezaei, 2015), we expect Chinese consumers who are quality conscious to be more sensitive to these product cues when making purchase decisions. Therefore,

H4: Quality consciousness is positively associated with brand prominence.

\subsection{Fashion consciousness and brand prominence}

Given fashion conscious consumers' emphasis on gaining social approval and recognition through seeking out new and fashionable products, their emphasis on prominent attributes may be dictated by the extent to which they are able to convey the impression of being in style or remaining current (Rezaei, 2015). Specifically, given its conspicuous and status revealing nature (Wang et al., 2004), fashion clothing represents an essential tool through which consumers gain face. Face in this regard refers to a sense of favorable social self-worth that an individual wants others to have of him or her in a relational and network 
context (Bao et al., 2003), a notion particularly common in a hierarchy and status-oriented culture such as China (Zhang and Kim, 2013). Accordingly, we argue that in expressing their individuality and uniqueness, Chinese fashion-conscious consumers are aspired to gain "face" and recognition from being trendy (Bao et al., 2003). This recognition is achieved when they use a well-established brand with a strong origin instead of donning those which may appear unknown or unacceptable to significant others (Bao et al., 2003). Consumption of brand-name fashion clothing with a strong origin allows fashion-conscious Chinese consumers to express their unique fashion-oriented images, positions or feelings to significant others within the social context. Thus, they are more likely to emphasize brand name and origin when making purchase decisions because these attributes convey fashion and social status (Li and Gallup, 1995). Therefore,

H5: Fashion consciousness is positively associated with brand prominence.

\subsection{Price consciousness and brand prominence}

Price conscious consumers exhibit the characteristic of being careful about product prices due to their emphasis on value for money (Wesley et al., 2006; Rezaei, 2015). They are often concerned with getting lower prices by looking for sale prices and making comparisons among the offerings on the market (Lysonski and Durvasula, 2003; Wesley et al., 2006; Rezaei, 2015). Therefore, we expect that with increasing levels of price consciousness, Chinese consumers are less likely to be concerned about brand name and origin. Given price conscious consumers' desire to get the best value for money (Zhou et al., 2010), they are less willing to pay the extra price for the distinctive and prominent attributes of goods (Rezaei, 2015), such as superior image or favorable country of origin. Instead, they focus on the utilitarian aspects of their shopping behavior, and are more concerned about the money spent 
and value received (Zhou et al., 2010). In this sense, brand-related issues are of little concern to the price conscious consumer. Therefore,

H6: Price consciousness is negatively associated with brand prominence.

\section{Research design}

\subsection{Sampling and data collection}

In testing the hypotheses, we followed the approach adopted by previous studies examining materialism in emerging markets by developing and administering a selfadministered survey in China (e.g., Liao and Wang, 2009; Zhang and Kim, 2013). As highlighted earlier, China appears to be an appropriate and fitting context to examine materialism because following significant socio-political-economic changes, the country is emerging as one of the world's leading economic powerhouses and most important consumer markets (Zhou et al., 2010). Chinese consumers are now having not only greater access to foreign brands and the Western life, but also a significant increase in spending power and the desire for internationally famous lifestyle and fashion brands (Bao et al., 2003; Liao and Wang, 2009; Zhang and Kim, 2013).

Following previous research (e.g., Park et al., 2007; O’Cass and Siahtiri, 2013), we employed the intercept method and targeted university students. We approached university students on campus and distributed 500 surveys across major universities in different provinces, such as Guangzhou and Beijing. University students are a good sample to evaluate the predisposition of future Chinese generation towards materialism for four reasons. First, recent research suggests materialism forms a significant part of the modern Chinese culture, which is passed on from one generation to the next (Zhang and Kim, 2013). Second, parents supply their children with excessive money to prove their care and love for them (Zhang and Kim, 2013). Third, education provides Chinese students with higher income in the future 
(McKinsey Global Institute, 2012), which allows them to pursue the materialist lifestyle they inherit from culture and parents. Fourth, previous studies also use university students to examine materialism (e.g., Park et al., 2007). We received in total 460 usable surveys, yielding a response rate of $92 \%$. Of 460 respondents, $30 \%$ of respondents were male university student. The mean age of the respondents was 22 years.

\subsection{Measures}

We sourced established measures from previous studies and adapted to suit the context of the current study. We operationalized materialism as a second-order formative construct with three first-order reflective components tapping success (five items), centrality (four items) and happiness (five items), based on the work of Richins (2004). Drawing from O'Cass and Siahtiri (2013), we measured quality consciousness (QC), fashion consciousness (FQ) and price consciousness (PC) with four items each. Lastly, we measured brand prominence (BP) with three items based on previous literature (e.g., Han et al., 2010). We also included age, gender and residence location as control variables.

We used two-step process to develop the survey (O'Cass and Siahtiri, 2014). First, we generated items from the extant literature; and second, we refined the items. We asked an expert panel comprising of academics within consumer behavior and branding to assess the content and face validity of items (O'Cass and Siahtiri, 2014). We developed the questionnaire in English. We ensured translation equivalence using the back-translation approach (O'Cass and Siahtiri, 2014). Before distributing the surveys, we conducted a pretest on 30 university students to ascertain item comprehension and readability. Aside from a few wording issues which called for minor changes, no major concerns were reported. In the cover letter which we attached to the questionnaire, informants were guaranteed confidentiality and anonymity to reduce social desirability bias (Podsakoff et al., 2003). 


\section{Results}

\subsection{Reliability and validity}

Following prior research (e.g., O'Cass and Siahtiri, 2013), we assessed the psychometric properties of constructs before testing the hypotheses. As shown in Table 1, all individual indicator loadings are significant $(t>1.96)$ and greater than the required benchmark of .50 . Further, the average variance extracted (AVE) and composite reliability (CR) estimates for each construct are greater than the recommended benchmarks of .50 and .70 , respectively. These findings provide evidence of satisfactory convergent validity.

--- Table 1 here -

\section{Table 1: Measurement items}

\section{Construct and items}

Materialism

Success $(\mathrm{AVE}=.53, \mathrm{CR}=.85)$

Some of the most important achievements in life include acquiring material possessions.

I place a lot of emphasis on the amount of material objects people own as a sign of success.

The things I own say a lot about how well I'm doing in life.

I like to own things that impress people.

Centrality $(\mathrm{AVE}=.52, \mathrm{CR}=.81)$

I try to keep my life simple, as far as possessions are concerned.

Buying things gives me a lot of pleasure.

I like a lot of luxury in my life. 
Happiness $(\mathrm{AVE}=.59, \mathrm{CR}=.88)$

I don't have all the things I really need to enjoy life.

My life would be better if I owned certain things I don't have.

I'd be happier if I owned nicer things.

I'd be happier if I could afford to buy more things.

It sometimes bothers me quite a bit that I can't afford to buy all the things I'd

like.

$Q C(\mathrm{AVE}=.66, \mathrm{CR}=.89)$

When it comes to purchasing products, I try to get the highest quality products.

In general, I usually try to buy the best overall quality.

I make special effort to choose the very best quality products.

$F C(\mathrm{AVE}=.75, \mathrm{CR}=.92)$

I keep up to date with the changing (i.e., latest) fashions.

The latest fashionable, attractive styling is important to me.

I generally try to keep up to date with the latest fashions.

I am fashion conscious.

$P C(\mathrm{AVE}=.76, \mathrm{CR}=.93)$

I will shop at more than one store to take advantage of low prices.

The money saved by finding low prices is usually worth the time and effort.

I would shop at more than one store to find low prices.

The time it takes to find low prices is usually worth the effort.

$B P(\mathrm{AVE}=.72, \mathrm{CR}=.89)$

When buying fashion clothing, I only look for branded ones.

When buying fashion clothing, I prefer to buy imported brands. clothing. 
Following previous studies (e.g, O’Cass et al., 2013), we tested discriminant validity. As shown in Table 2, the square root of all AVE estimates are greater than the off-diagonal correlation estimates between the corresponding constructs. Further, adopting the approach recommended by, the reliability estimates of any two constructs shown in Table 2 are greater than their corresponding correlation value.

--- Table 2 here ---

Table 2: Construct-level descriptive statistics and correlation matrix

\begin{tabular}{lccccccccccc}
\hline Construct & Mean & SD & AVE & CR & 1 & 2 & 3 & 4 & 5 & 6 & 7 \\
\hline 1. Success & 4.40 & 1.27 & .53 & .85 & .73 & & & & & \\
2. Centrality & 3.86 & 1.00 & .52 & .81 & .42 & .72 & & & & \\
3. Happiness & 4.79 & 1.29 & .59 & .88 & .52 & .32 & .77 & & & \\
4. QC & 5.30 & 1.13 & .66 & .89 & .17 & .16 & .16 & .81 & & \\
5. FC & 3.77 & 1.41 & .75 & .92 & .20 & .46 & .19 & .20 & .87 & \\
6. PC & 4.71 & 1.42 & .76 & .93 & .15 & .11 & .19 & .11 & .21 & .87 \\
7. BP & 3.25 & 1.42 & .72 & .89 & .31 & .43 & .24 & .20 & .30 & .05 & .85 \\
\hline
\end{tabular}

Notes: $\mathrm{SD}=$ standard deviation;

Square root of AVE are shown in the italicised diagonal entries.

Given materialism is modelled in the current study as a Type-II, second-order formative construct, the concepts of internal consistency and convergent validity are not applicable (Diamantopoulos and Winklhofer, 2001). Therefore, we followed the procedure of prior research (e.g., Wilden et al., 2013) and assessed its psychometric properties through examining indicator weights or paths and VIF values. As shown in Table 1, the path coefficients of the three components of materialism ( .46 for success, .27 for centrality and .51 for happiness) are positive and significant $(\mathrm{p}<.01)$. An examination of the VIF values among 
the three components of materialism also suggested that multicollinearity is not an issue given the values are well below the cut-off of five (Hair et al., 2011). These findings provided support for the reliability and validity of the measurement of materialism as a second-order construct comprising three first-order components.

\subsection{Hypotheses testing}

In testing the hypotheses, we employed multivariate regression analysis with an ordinary least squares estimator (Aiken and West, 1991). Our findings are reported in Table 3. Step 2 of Model 1 shows materialism has a positive effect on $\mathrm{QC}(\beta=.20, p<.01)$, supporting H1. Step 2 of Model 2 represents a positive and significant relationship between materialism and FC $(\beta=.31, p<.01)$, supporting H2. Finally, Step 2 of Model 3 indicates the relationship between materialism and $\mathrm{PC}$ is significant and positive $(\beta=.22, p<.01)$, rejecting $\mathrm{H} 3$.

Table 3: Regression results

\begin{tabular}{|c|c|c|c|c|c|c|c|c|c|}
\hline \multirow{2}{*}{ Variables } & \multicolumn{2}{|c|}{ Model 1: QC } & \multicolumn{2}{|c|}{ Model 2: FC } & \multicolumn{2}{|c|}{ Model 3: PC } & \multicolumn{3}{|c|}{ Model 4: BP } \\
\hline & Step 1 & Step 2 & Step 1 & Step 2 & Step 1 & Step 2 & Step 1 & Step 2 & Step 3 \\
\hline Age & -.05 & -.05 & .01 & .01 & -.05 & -.04 & -.04 & -.03 & -.03 \\
\hline Gender & $-.09 \dagger$ & $-.10 *$ & $.10^{*}$ & $.08 \dagger$ & .02 & .01 & $-.14 * *$ & $-.16 * * *$ & $-.16 * * *$ \\
\hline City & -.03 & -.01 & $-.14 * *$ & $-.11 *$ & -.04 & -.02 & -.05 & -.03 & -.01 \\
\hline Materialism & & $.20 * * *$ & & $.31 * * *$ & & $.22 * * *$ & & $.37 * * *$ & $.30 * * *$ \\
\hline QC & & & & & & & & & $.10^{*}$ \\
\hline $\mathrm{FC}$ & & & & & & & & & $.21 * * *$ \\
\hline $\mathrm{PC}$ & & & & & & & & & -.07 \\
\hline $\mathrm{R}^{2}$ & .01 & .05 & .03 & .13 & .00 & .05 & .02 & .16 & .21 \\
\hline$\Delta \mathrm{R}^{2}$ & & $.04 * * *$ & & $.10 * * *$ & & $.05 * * *$ & & $.13 * * *$ & $.05 * * *$ \\
\hline$F$ value & 1.49 & 5.87 & 4.27 & 16.28 & .60 & 6.16 & 3.32 & 20.95 & 16.9 \\
\hline
\end{tabular}


Notes: $†<.10 ; * p<.05 ; * * p<.01 ; * * * p<.001$; standardized regression coefficients are reported

Step 3 of Model 4 presents a positive and significant relationship between QC and BP $(\beta=.10, p<.05)$, supporting H4. Step 3 of Model 4 shows a positive and significant relationship between $\mathrm{FC}$ and $\mathrm{BP}$ is positive and significant $(\beta=.21, p<.01)$, supporting $\mathrm{H} 5$. We found no support for H6, as shown in Step 3 of Model 4, the relationship between PC and $\mathrm{BP}$ is negative but not significant $(\beta=-.07, \mathrm{~ns})$.

Given the above findings, we performed additional analyses to determine whether QC, FC, and PC mediated the relationship between materialism and BP. To this end, we followed the procedure recommended by Baron and Kenny (1986). Our findings are reported in Table 3. First, we assessed whether materialism influenced BP. As seen in Step 2 of Model 4, the relationship between materialism and BP is positive and significant $(\beta=.37, p<.01)$. Second, we assessed whether materialism influenced the mediating variables (QC, FC, and PC). This is essentially H1 to H3 (Step 2 of Models 1, 2 and 3), which we discussed earlier. Third, we assessed whether the mediating variables influenced BP. This is essentially H4 and H5, which were supported (Step 3 of Model 4). Fourth, we assessed whether the previously significant influence of materialism on b BP dropped substantially or became insignificant after the inclusion of the mediating variables. As shown in Step 3 of Model 4, the effect of materialism on $\mathrm{BP}$ reduced in size. These findings suggest that $\mathrm{QC}$ and $\mathrm{FC}$ mediate the relationship between materialism and BP. In corroborating these findings, we followed the approach recommended by Preacher and Hayes (2004), and applied the bootstrapping method. The results showed that the indirect effect of materialism on BP through QC is statistically significant $(\mathrm{a} \times \mathrm{b}=.038)$, with bias-corrected $95 \%$ confidence intervals excluding zero (.013 to .079). The bootstrapping analysis also showed that the indirect influence of materialism on $\mathrm{BP}$ via $\mathrm{FC}$ is statistically significant $(\mathrm{a} \times \mathrm{b}=.107)$, with bias-corrected $95 \%$ confidence intervals excluding zero (.060 to .171). 


\section{Discussion and implications}

Chinese consumers are increasingly emulating the Western-style material culture and indulging themselves with luxury and prominent brands (O’Cass and Siahtiri, 2013). Despite the importance of Chinese market in selling superb brands, we still lack a clear explanation of underlying mechanism that materialist Chinese use to select prominent brands. This study aimed to advance the current literature on materialism by explaining how and why Chinese consumers pursuing the material lifestyle favor brands with prominent attributes. We extended the work by Flynn et al. (2016), Zhang and Kim (2013), Han et al. (2010) and Park et al. (2010), and proposed that the missing link between consumers' materialistic values and BP among Chinese consumers is consumers' QC, FC and PC. Integrating Chinese cultural values with self-expansion theory, we argued that Chinese consumers see brands as extensions of their selves, therefore; they choose brands that are prominent in their minds. We further argued that prominent attributes of a brand is an important factor influencing Chinese consumers' purchase decision. In doing so, we advance marketing theory and practice in several ways.

We contribute to the current literature by shedding light on the process through which materialism influences brand prominence in an emerging market. We show that the path from materialism to BP is indirect and takes place through quality and fashion consciousness. This finding suggests that as consumers' level of materialism increases; they are more likely to select prominent brands because of their heightened consciousness of fashion and quality in brands. Consistent with previous research (Zhang and Kim, 2013; Liao and Wang, 2009), we suggest that Chinese consumers use specific brands for intrinsic gratification, and as a symbol of success, wealth and status to promote their face. However, we extend these works by articulating reasons behind their behaviors. We extend previous studies by proposing being 
conscious of fashion and quality in brands allows materialists to discern which specific brands facilitate the reflection of their selves to significant others in order to derive happiness and signal success. In promoting face, the perception of surrounding others manifests through behaviors emphasizing fashion and quality consciousness when choosing prominent brand.

Interestingly, contrary to our expectations, materialism is found to have a positive influence on PC within the Chinese context. This suggests that with increasing levels of materialism, Chinese consumers tend to be more price conscious. A possible explanation is that although China's average family income has been rising dramatically (Wang et al., 2004), the nation still upholds the Confucian ideology and emphasizes long-term orientation (Zhou et al., 2010). This suggests that the Chinese heritage of being long-term-oriented prevails over the fad of materialism, such that consumers are living the material lifestyle through value-conscious and future-oriented means, despite their exponential growth in spending power. The other possible explanation is that older generation in China experienced social-political-economic turbulence in their early ages and passed it to their children (Zhang and Kim, 2013). As such, they train their children to live happily, but use their wealth wisely.

The same could also be said of why the influence of price consciousness on brand prominence was not significant. It is said that long-term orientation breeds virtues emphasising future rewards, in particular, perseverance and thrift (Hofstede, 2005; Zhou et $a l ., 2010)$. Consumers in China are generally having greater spending power and desire to impress others through consuming name brands (Liao and Wang, 2009; Zhou and Kim, 2013). However, it does not negate the possibility of being functionally driven and seek some utilitarian benefits in the brands they choose, instead of focusing solely on what the brands mean to them (and their significant others).

Our findings have several implications for practice. We encourage marketing managers who wish to target materialistic consumers in China to design products that offer long-term 
value. Marketing managers have to design their communication messages carefully to reflect that consumption of the brand provides consumers with success and happiness in life. Perhaps marketing managers can highlight the fashion and quality of their products in their communication with materialist consumers. If materialist consumers confer the brand as quality and fashionable, the products become more appealing to them. Marketing managers have to design their pricing strategies carefully and outline the value consumers receive in order to justify the price. Our findings also suggest that marketing managers in emerging countries should be aware of the effect of irrational buying. Our findings suggest that consumers carefully assess prices, however; they demonstrate some levels of irrationality in purchasing prominent brands that help them stand out of the crowd.

\section{Limitations and future research}

While our study advances knowledge on materialism, it comes with several limitations, which opens up opportunities for future research. We explored the paths through which materialists choose prominent brands. However, we did not examine if these choices and factors lead to actual purchase. Future researchers may extend our model and examine if these factors result in purchasing the brand. Further, future researchers can consider other mediators or contingencies that translate the effect of materialism to BP (e.g., need for uniqueness). Lastly, future research may consider some contingencies between materialism and price consciousness to understand if their relationships changes (e.g., need for uniqueness).

\section{References:}

Aiken, L., and West, S. (1991). Multiple regression testing and interpreting interactions. Newbury Park, CA: Sage. 
Aron, A., Mashek, D., McLaughlin-Volpe, T., Wright, S., Lewandowski, G., \& Aron, E. N. (2005). Including Close Others in the Cognitive Structure of the Self. In M. W. Baldwin (Ed.), Interpersonal cognition. pp. 206-232. New York: Guilford Press.

Bao, Y., Zhou, K., and Su, C. (2003). Face consciousness and risk aversion: Do they affect consumer decision-making? Psychology and Marketing, 20(8), 733-755.

Baron, R., and Kenny, D. (1986). The moderator-mediator variable distinction in social psychological research: Conceptual, strategic, and statistical considerations. Journal of Personality and Social Psychology, 51(6), 1173-1182.

Belk, R. (1985). Materialism: Trait Aspects of Living in the Material World. Journal of Consumer Research, 12(3), 265. doi: 10.1086/208515

Chan, W., To, C., and Chu, W. (2015). Materialistic consumers who seek unique products: How does their need for status and their affective response facilitate the repurchase intention of luxury goods? Journal of Retailing and Consumer services, 27(Nov), 110.

Diamantopoulos, A., and Winklhofer, H. M. (2001). Index construction with formative indicators: An alternative to scale development. Journal of Marketing Research, $38(2), 269-277$.

Eastman, J., and Eastman, K. (2011). Perceptions of status consumption and the economy. Journal of Business and Economics Research (JBER), 9(7), 9-20.

Evangelidis, I., and Levav, J. (2013). Prominence versus dominance: How relationships between alternatives drive decision strategy and choice. Journal of Marketing Research, 50(6), 753-766.

Flynn, L., Goldsmith, R. and Pollitte, W., 2016. Materialism, Status Consumption, and Market Involved Consumers. Psychology and Marketing, 33(9),761-776. 
Fischer, G. W., Carmon, Z., Ariely, D., and Zauberman, G. (1999). Goal-based construction of preferences: Task goals and the prominence effect. Management Science, 45(8), 1057-1075.

Gentina, E., Butori, R., Rose, G., and Bakir, A. (2014). How national culture impacts teenage shopping behavior: Comparing French and American consumers. Journal of Business Research, 67(4), 464-470.

Gil, L.A., Kwon, K.-N., Good, L.K., and Johnson, L. W. (2012). Impact of self on attitudes toward luxury brands among teens. Journal of Business Research, 65(10), 1425-1433.

Goldsmith, R., Flynn, L. , and Clark, R. (2012). Materialistic, brand engaged and status consuming consumers and clothing behaviors. Journal of Fashion Marketing and Management: An International Journal, 16(1), 102-119.

Goldsmith, R., Flynn, L., and Kim, D. (2010). Status consumption and price sensitivity. Journal of Marketing Theory and Practice, 18(4), 323-338.

Hair, J. , Ringle, C. , and Sarstedt, M. (2011). PLS-SEM: Indeed a silver bullet. Journal of Marketing Theory and Practice, 19(2), 139-152.

Heaney, J., Goldsmith, R., and Jusoh, W. (2005). Status Consumption Among Malaysian Consumers. Journal of International Consumer Marketing, 17(4), 83-98.

Hofstede, G. (2005). Cultures and organizations: software of the mind. McGraw-Hill, NY.

Kim, D., and Jang, S. (2014). Motivational drivers for status consumption: A study of Generation Y consumers. International Journal of Hospitality Management, 38, 3947.

Li, D., and Gallup, A. (1995). In search of the Chinese consumer. China Business Review, 22(5), 19-22.

Liao, J., and Wang, L. (2009). Face as a mediator of the relationship between material value and brand consciousness. Psychology and Marketing, 26(11), 987-1001. 
Lichtenstein, D., Ridgway, N., and Netemeyer, R. (1993). Price Perceptions and Consumer Shopping Behavior: A Field Study. Journal of Marketing Research, 30(2), 234.

Mulyanegara, R, Tsarenko, Y. \& Anderson, A. (2009). The Big Five and brand personality: Investigating the impact of consumer personality on preferences towards particular brand personality. Journal of Brand Management 16 (4), 234-247.

O'Cass, A., Lee, W., and Siahtiri, V. (2013). Can Islam and status consumption live together in the house of fashion clothing? Journal of Fashion Marketing and Management: An International Journal, 17(4), 440-459.

O'Cass, A., and Siahtiri, V. (2013). In search of status through brands from Western and Asian origins: Examining the changing face of fashion clothing consumption in Chinese young adults. Journal of Retailing and Consumer Services, 20(6), 505-515.

O'Cass, A., and Siahtiri, V. (2014). Are young adult Chinese status and fashion clothing brand conscious? Journal of Fashion Marketing and Management: An International Journal, 18(3), 284-300.

Park, C., MacInnis, D., Priester, J., Eisingerich, A., and Iacobucci, D. (2010). Brand attachment and brand attitude strength: Conceptual and empirical differentiation of two critical brand equity drivers. Journal of Marketing, 74(6), 1-17.

Park, H., Burns, L., and Rabolt, N. (2007). Fashion innovativeness, materialism, and attitude toward purchasing foreign fashion goods online across national borders. Journal of Fashion Marketing and Management: An International Journal, 11(2), 201-214.

Preacher, K. , and Hayes, A. (2004). SPSS and SAS procedures for estimating indirect effects in simple mediation models. Behavior Research Methods, Instruments, and Computers, 36(4), 717-731. 
Rezaei, S. (2015). Segmenting consumer decision-making styles (CDMS) toward marketing practice: A partial least squares (PLS) path modeling approach. Journal of Retailing and Consumer Services, 22(1), 1-15.

Richins, M., and Dawson, S. (1990). Measuring material values: A preliminary report of scale development. NA-Advances in Consumer Research, 17.

Richins, M., and Dawson, S. (1992). A consumer values orientation for materialism and its measurement: Scale development and validation. Journal of Consumer Research, 19(3), 303-316.

Van Reijmersdal, E. A., Rozendaal, E., and Buijzen, M. (2012). Effects of prominence, involvement, and persuasion knowledge on children's cognitive and affective responses to advergames. Journal of Interactive Marketing, 26(1), 33-42.

Wang, C., Siu, N., and Hui, A. (2004). Consumer decision-making styles on domestic and imported brand clothing. European Journal of Marketing, 38(1/2), 239-252.

Wesley, S., LeHew, M., and Woodside, A. (2006). Consumer decision-making styles and mall shopping behavior: Building theory using exploratory data analysis and the comparative method. Journal of Business Research, 59(5), 535-548.

Wilden, R., Gudergan, S., Nielsen, B., and Lings, I. (2013). Dynamic capabilities and performance: Strategy, structure and environment. Long Range Planning, 46(1), 7296.

Zhang, B., and Kim, J. (2013). Luxury fashion consumption in China: Factors affecting attitude and purchase intent. Journal of Retailing and Consumer services, 20(1), 6879.

Zhou, J., Arnold, M. , Pereira, A., and Yu, J. (2010). Chinese consumer decision-making styles: A comparison between the coastal and inland regions. Journal of Business Research, 63(1), 45-51. 
Zeithaml V. (1998). Consumer perceptions of price, quality, and value: a means model and synthesis of evidence. Journal of Marketing, 52(1), 2-22. 